\title{
Subjetividade, Cultura e Poder
} Politizando Masculinidades Negras

Em "O Mundo se Despedaça", Chinua Achebe, "fundador" do romance africano, estrutura, através do ponto de vista de um homem, a narrativa de decadência e desorganização colonial do povo de Uomófia, vila Ibo, localizada no que hoje é a Nigéria. E o romance pode ser lido como atravessado pelas contradições e ansiedades masculinas de Okonkwo, o homem forte filho e pai de homens fracos. Os valores da comunidade aparecem materializados, encarnados na adequada conduta masculina. A força e a virilidade masculina, o cultivo do inhame, as bravatas guerreiras, todo o complexo do ethos masculino aparece retratado em Achebe como fundação da integridade da cultura Ibo; e não é à toa que a debilidade da comunidade principia pela debilidade de seus homens.

Pierre Bourdieu em "A Casa Kabyle ou o Mundo às Avessas", de modo talvez mais consistente que em "A Dominação Masculina", demonstra como o mundo Kabyle objetivado, tornado matéria exterior e impositiva, autonomizado, como a verdadeira natureza das coisas, é um mundo que transcreve a ordenação dos gêneros na realidade social, instituída de modo material através de meios simbólicos, o que configura o gênero como elemento estruturante da ordem social objetivada. De modo que, como entre os Ibo, a ordem social é a ordem dos gêneros, na qual a masculinidade tem lugar estruturante. E nesse sentido confrontar a masculinidade é confrontar a sociedade, e vice-versa.

Em “O parentesco é sempre tido como heterossexual?" Judith Butler discute as prerrogativas do Estado na regulação do parentesco e sua confrontação pela "nação", imaginada como heterossexual e autoregulada, de modo ideologicamente individualizado, enquanto o Estado, árbitro não-ideológico, se debruça sobre as subjetividades e a vida privada: 
Os debates se centram não somente nas questões do que é a cultura? Quem deve ser admitido? Como devem ser reproduzidas as questões de cultura?, mas também no status do Estado, e, em particular, no poder de conferir ou negar reconhecimento a formas de alianças sexuais. (...) Para ambos os lados do debate, o problema não é só a questão de quais relações de desejo devem ser legitimadas pelo Estado, mas de quem pode desejar o Estado, quem pode desejar o desejo do Estado (p. 233).

O que gostaríamos de enfatizar com os três exemplos acima são as co-determinações entre a imaginação e/ou regulação do gênero e de sujeitos de gênero, e as formas de organização social. Ou ordem social, se preferirmos uma formulação mais dramática. E, obviamente, quando nos referimos a sujeitos de gênero queremos dizer homens, mulheres e outras categorias local e culturalmente contingentes. A formação dos sujeitos, dos homens, dos "sujeitos-homem", é solidária e co-dependente da própria invenção da sociedade em suas formas cambiantes. Isso deveria ser uma obviedade, uma daquelas platitudes sociológicas que não espantam mais ninguém. Mas, todavia, não é assim. No caso da consciência social vernácula, para além da naturalização dos gêneros, elemento central da ordem social moderna, tendemos a ver os homens como mais naturais e espontâneos. Os homens, ao menos os "homens de verdade", não se produzem ou se enfeitam, nem pensam em geral sobre si mesmos como artefatos culturais e históricos, costurados com músculos e cores sóbrias. Em oposição às mulheres e outros sujeitos de gênero, vistos como adornados, ou como adornos, eles próprios. Mulheres e "viados" são espalhafatosos e afetados, e homens são apenas como são. Ora, os homens são tais quais são, na mesma medida mulheres e gays, todos atados as contradições e horizontes de sentido sem falar nas relações materiais de produção social - que tornam real a vida em sociedade. A dimensão artefactual é nesse sentido também política, se concordamos com a posição foucaultiana sobre a produção de sujeitos como sujeição/subjetivação. Nos tornamos sujeitos na mesma medida em que tornamos concreta a rede de relações sociais materiais/discursivas - que dão sustentação as rotinas reguladas que chamamos de sociedade.

Dizemos isso para salientar o impulso e a provocação inicial que motivou a organização desse dossiê. Reconhecer visibilidade e densidade empírica e teórica para a discutir a masculinidade para muito além de ideais normativos sobre como os homens deveriam ser ou o que deveriam fazer para se tornarem homens de verdade, ou respeitáveis, ou 
para fazer coincidir a concretude de nossas subjetividades tortuosas a um ideal de masculinidade (nesse caso em particular, e com inúmeras consequências discutidas nesse dossiê) negra. A conjunção entre raça e gênero nesse caso, parece confirmar, em grande parte, a discussão sobre masculinidades negras contemporâneas, próxima demais da propensão normativa quando não subjetivista, articulada em torno de questões como: o homem negro pode ser um bom pai? O homem negro pode ser homem fora de "masculinidades tóxicas"? O que fazer para que o homem negro e a mulher negra se encontrem em relações reciprocas e bem ajustadas? Homens negros gays podem ter relações não mediadas pela fetichização dos próprios corpos? Perguntas que figurariam muito bem em manuais pós-modernos de autoajuda interseccional.

Lemos tanto Fanon recentemente, mas parece que esquecemos algumas de suas principais lições. Dentre estas, as mais importantes, que nos lembram que somos prisioneiros de nossa própria historicidade, e que esta se lança sobre nossa consciência, mantendo em aguda suspensão a nossa relação - socialmente mediada - com nosso corpo. $\mathrm{O}$ programa de desordem total do mundo (colonial) que Fanon advoga não admite reformas cosméticas que nos façam nos sentir "melhor". Se sentir "bem" não está entre os objetivos políticos da crítica fanoniana, muito menos encontrar a boa medida para relação como o nosso corpo ou sexualidade, parceiro ou parceira, ou encontrar o caminho para a vida "saudável" ou estabilidade emocional. Nada disso! Às favas com a estabilidade emocional, quando nosso mundo é um mundo de fogo e pólvora, posto em movimento pela velha violência.

A antropologia social tem sido acusada, e é culpada, de muitos pecados, mas uma de suas lições mais importantes - que transparece quando, apesar de odiarmos a teoria funcional, amamos a etnografia realista - permanece subvalorizada no pensamento crítico. Assumir a difícil e libertadora distância de nossos próprios valores, linguagens e horizonte sócio-histórico. Bem evidente que essa tarefa é, de rigor, impossível. Mas seu objetivo ou desiderato não é de fato nos despir de nosso "horizonte", mas criar desconforto e desconfiança com relação a este. Nesse sentido, a antropologia sempre foi contra nós mesmos. Assim, acomodar-se a uma agenda de questões imposta pelo próprio horizonte social que deveria ser questionado e desmontado é no mínimo autocomplacência epistemológica. Ou renúncia crítica. Como nos programas neopentecostais da madrugada que perguntam: "Os orixás são fruto de doenças mentais ou de possessão demoníaca?”, a própria 
pergunta já embute a resposta. O próprio repertório conceitual, os valores e categorias de quem pergunta, definem inteiramente as respostas possíveis e posicionam os elementos dessa relação em um círculo vicioso cultural. E por isso a ênfase em um ponto de vista crítico, capaz de fazer perguntas desde fora do círculo.

Nesse sentido, a proposta do dossiê em politizar masculinidades negras aponta na direção oposta de ideais normativos, quer sejam heterossexistas ou patriarcais, burgueses e individualistas, europeus ou afrocêntricos, que parecem incidir extensamente sobre nossa imaginação crítica, na medida em que estes não almejam distanciar-se ou desconfiar dos contextos sócio-históricos que definiram estes mesmos "sujeitos", "categorias" e "objetos", etc. Como, aliás, colocou recentemente Mara Viveros (2018). Inversamente buscamos reconhecer como os homens "são" (ou não são "nada"), ou como conseguem precariamente ser em contextos muito diversos, muito complexos e muito estruturados, reunindo aqui excepcionais contribuições multidisciplinares em torno de questões amplificadoras.

Assim, em "A Ordem Pública e as Masculinidades Negras: O Controle Objetivo e Subjetivo do Homem Negro", se ataca de partida o problema da correlação apontada a cima, de modo mais circunscrito conceitualmente falando, interrogando o conceito de "ordem pública" como um dispositivo de controle social - biopolítico - voltado para trabalhadores e outros sujeitos que demandariam disciplina e controle, em termos de classe e raça. $\mathrm{O}$ autor enxerga uma continuidade colonial nos modos de operação e legitimação da "ordem" justamente na regulação dos sujeitos e nesse sentido conduz, a partir de entrevistas individuais, o debate para a produção de subjetividades negras. De modo concreto sugere que as políticas de governabilidade na modernidade racializada, exigem a projeção/produção de subjetividades sob o paradigma necropolítico da "lógica do cerco", o que o permite abordar questões ligadas ao mundo do trabalho, a relação com a polícia e à paternidade, no ambiente social definido por uma ordem pública e política essencialmente antinegra e que localiza o homem negro como essencialmente perigoso.

Em "Paternidade e Masculinidades Negras Circunscritas: Exercícios de Autorreflexão Emancipatórios” os autores oferecem outra perspectiva para as formas sociais de masculinidade negra, nesse caso justamente definidas pela paternidade como "um ato de resistência $e$ reexistência", através de entrevistas com homens adultos entre 40 e 70 
anos de idade, que buscam se equilibrar entre as pressões da sociedade de classes racializada e a reinvenção da masculinidade através do cuidado. Os autores enfatizam, também nesse caso, as contradições e impasses vividos no plano subjetivo, como espaço de agência social desses sujeitos, mesmo em meio aos traumas do colonialismo patriarcal.

De pais e trabalhadores, para crianças participantes em uma manifestação cultural fascinante, que "trata", por meios simbólicos do trauma histórico da escravidão, manipulando de modo notável elementos do "repertório" performático do saber negro no Recôncavo da Bahia. Em seu texto complexo e igualmente notável Maria José Villares Barral Villas Boas, descreve e interpreta a performance popular do "nêgo fugido", onde se veem representados diversos personagens, que teatralizam a memória histórica e o jogo dos gêneros e representações de modo surpreendentemente plástico. A autora discute nesse sentido a recente inclusão de mulheres e como, ao mesmo tempo, na performance se atualiza "uma performatividade de gênero específica $e$ compartilhada, produzindo uma noção de masculinidade hegemônica e contra hegemônica que atravessa meninas e meninos". Dando ênfase nesse caso a agência reflexiva dos sujeitos que manipulam a performance/ritual como vistas a tensionar e manipular categorias sociais, como elementos subjetivos de releitura histórica.

No texto seguinte, a personagem Luke Cage é tomada como expediente para discutir modos de enunciação de subjetividades negras para homens racializados. Centrando sua análise no rendimento semiótico e político do capuz (hoodie), símbolo e estigma de masculinidades negras vulnerabilizadas como perigosas e tristemente emblemático, após o assassinato de Trayvon Martin, a autora discute como a personagem de quadrinhos, retomado pela série da Netflix, permite discutir modos de visibilidade negra e suas tensões interseccionais, como uma instância produtiva e produtora de subversões como a ressignificação do capuz como marca do herói. Como conclui então a autora, opera-se aqui no registro da "atualização do que é dizível, pensável, sobre as subjetividades masculinas negras”.

Fábio Araujo Oliveira e Paulo Melgaço Júnior se voltam em seus artigos respectivos para o universo escolar, espaço institucional central na modernidade para a definição e redefinições de identidade, e para a reprodução dos padrões de desigualdade e conformação social de gênero em nossas sociedades. Em "Masculinidades Negras no Livro Didático De Língua Portuguesa", Oliveira elege a análise do discurso para uma 
abordagem que ponha a nu a ideologização da raça e sua efetiva construção, não apenas por meios discursivos, mas também visuais, o que se conecta ao debate sobre regimes de visualidade como desenvolvido no artigo anterior. A questão essencial para o autor tem a ver com a representação da subjetividade negra e como ela pode ser interpelada ideologicamente no ambiente escolar formativo. Paulo Melgaço, por sua vez, em "Narrativas de adolescentes negros: entre masculinidades, cotidiano escolar e vivências" mergulha no cotidiano escolar do $9^{\circ}$ ano de uma escola pública em Duque de Caxias no Rio de Janeiro, para, através da voz dos adolescentes que articulam a própria compreensão em torno do significado de "ser homem", revelam trajetórias e alternativas diversas, muito além de estereótipos e modelos fixos para a identidade de gênero e a sexualidade.

Em "Notas Etnográficas sobre Homens Negros Balizadores de Fanfarra em Salvador", voltamos ao Recôncavo da Bahia e ao universo da performance, para nessa pesquisa inovadora e instigante de Vinicius Santos da Silva Zacarias, nos acercarmos do universo da "fechação" e do "viadeiro" dos rapazes negros que performam como "balizas de fanfarra" nos desfiles cívicos em Salvador e em seu entorno. O fenômeno reúne de forma surpreendente o nacionalismo cultural e regionalismos, releituras histórico-performáticas e produção contra hegemônica de subjetividades masculinas, negras e "viadas". Complexas e densas negociações entre a "invenção da tradição" e a produção de um (in)conformismo de gênero, queer e popular, podem ser discutidas graças ao dedicado trabalho etnográfico do autor.

Os dois últimos textos reunidos no dossiê escapam criativamente ao quadro estreitos dos gêneros acadêmicos, desestabilizando as formas convencionais de produção de conhecimento. Em "Meninos negros vão ao cinema: inovações nas representações cinematográficas como reinvenção das estéticas negras”, o autor buscando ressaltar a pluralidade dos sujeitos "como indivíduos múltiplos e heterogêneos", propõe o cinema como uma "pedagogia" para combater estereótipos e fixações racializadas, e é a partir dessa experiência que o texto nos oferece algumas reflexões, ao lançar mão da análise de obras audiovisuais como o clássico "Rio 40 Graus", de Nelson Pereira dos Santos ou o contemporâneo "Cidade de Deus", com o objetivo de testar e explorar os limites pedagógicos da utilização do audiovisual, o que se coloca no texto como uma proposição crítica. E, finalmente, em "Trajetória, experiência e corpo negro em cena: reflexões e 
apontamentos de um pesquisador iniciante" podemos concluir de modo sensível e em primeira pessoa, acompanhando a trajetória reflexiva de Daniel de Souza Campos. A reflexividade aqui é modelo epistemológico de reflexão sobre uma situação ou conjuntura racializada, o ambiente médico-hospitalar onde o autor transita de modo situado, mas também pode ser tomada como a categoria sociológica que descreve o automonitoramento da vida cotidiana. Como coloca Daniel, todavia, o seu objetivo geral, que de certa forma emula e tensiona nossa ambição nesse dossiê, seria representar sua "trajetória pessoal, experiência de pesquisa, de sobrevivência e de subversão, (para) poder contribuir, gerando incômodos, questionando as estruturas que insistem em nos aprisionar, exterminar e (in)visibilizar".

Osmundo PINHO

Rolf Malungo de SouzA

\section{Referências}

ACHEBE, Chinua. O Mundo se Despedaça. São Paulo. Editora Ática 1983. pp. 12-74.

BOURDIEU, Pierre. A casa kabyle ou o mundo às avessas. Cadernos de Campo (São Paulo, 1991), São Paulo, v. 8, n. 8, p. 147-159, mar. 1999.

BUTLER, Judith. O Parentesco é Sempre Tido como heterossexual? Cadernos Pagu. No. 21. 2003a. pp. 219-26o.

VIVERos, Mara. As Cores da Masculinidade. Expêriencias Interseccionais e Práticas de Poder na Nossa América. Rio de Janeiro. Papeis Selvagens. 2018. 